\title{
Clarification on: "Pectoral nerves I block is associated with a significant motor blockade with no dermatomal sensory changes"
}

\author{
M. S. Raghuraman, MD
}

Received: 20 August 2018/Revised: 20 August 2018/Accepted: 20 August 2018/Published online: 26 September 2018

(C) Canadian Anesthesiologists' Society 2018

\section{To the Editor,}

The recent article from Desroches et al. ${ }^{1}$ observed that the pectoral nerves (PECS) I block produced only motor blockade, sparing the sensory component. Some clarification is likely warranted. For example, one study has previously shown that the PECS II block was successful as a sole technique in conservative breast surgeries. ${ }^{2}$ Although that study used a PECS II block (i.e., involving both pectoral and pectoral-serratus anterior components), it is very important to note that it was used as a sole technique. Assuming that at least the medial one-third of the mastectomy incision would come under the "pectoral component" (such as would be covered by a PECS I block), this would not have been possible without the sensory blockade in that area. A possible explanation for these apparent differences in sensory coverage in these studies may have been due to the anatomical variations, though this is only speculation.

Furthermore, Desroches et al. ${ }^{1}$ have cast doubt over the "pectoral component" of the PECS II block and cited a study by Hetta and Rezk ${ }^{3}$ as support. However, if one analyzes the results of that study, ${ }^{3}$ I suspect that sparing the pectoral component would have probably resulted in inferior quality of this modified PECS II. Hence, I believe that the pectoral component is important and the other component (pectoral-serratus) is optional based on the type of surgery and the extent of the incision.

An additional point that needs clarification is that Desroches et al. stated that only one placebo-controlled study has assessed

This letter is accompanied by a reply. Please see Can J Anesth 2018; 65: this issue.

M. S. Raghuraman, MD ( $\square)$

Department of Anesthesiology, Sri Venkateshwaraa Medical College Hospital and Research Centre, Ariyur, Puducherry, India e-mail: drraghuram70@gmail.com the efficacy of PECS II. However, Hassn et al. published a study in 2016, which also analyzed the PECS II with a placebo control. ${ }^{4}$ That study showed that bupivacaine combined with dexmedetomidine, when compared with the placebo group, resulted in a significant reduction in analgesic requirements in the immediate postoperative period as well as benefits such as better patient satisfaction and quality of life up to six months follow-up. ${ }^{4}$ Nevertheless, the paucity of reported studies containing placebo controls could be due to concerns from the Institutional Review Boards as well as difficulty convincing the study patients to undergo an invasive technique such as PECS block when only injecting a placebo.

Conflicts of interest None declared.

Editorial responsibility This submission was handled by Dr. Hilary P. Grocott, Editor-in-Chief, Canadian Journal of Anesthesia.

\section{References}

1. Desroches J, Belliveau M, Bilodeau C, Landry M, Roy M, Beaulieu $P$. Pectoral nerves I block is associated with a significant motor blockade with no dermatomal sensory changes: a prospective volunteer randomized-controlled double-blind study. Can J Anesth 2018; 65: 806-12.

2. ELdeen $H M$. Ultrasound guided pectoral nerve blockade versus thoracic spinal blockade for conservative breast surgery in cancer breast: a randomized controlled trial. Egypt J Anaesth 2016; 32: 29-35.

3. Hetta DF, Rezk KM. Pectoralis-serratus interfascial plane block vs thoracic paravertebral block for unilateral radical mastectomy with axillary evacuation. J Clin Anesth 2016; 34: 91-7.

4. Hassn AM, Zanfaly HE, Biomy TA. Pre-emptive analgesia of ultrasound-guided pectoral nerve block II with dexmedetomidinebupivacaine for controlling chronic pain after modified radical mastectomy. Res Opin Anesth Intensive Care 2016; 3: 6-13. 